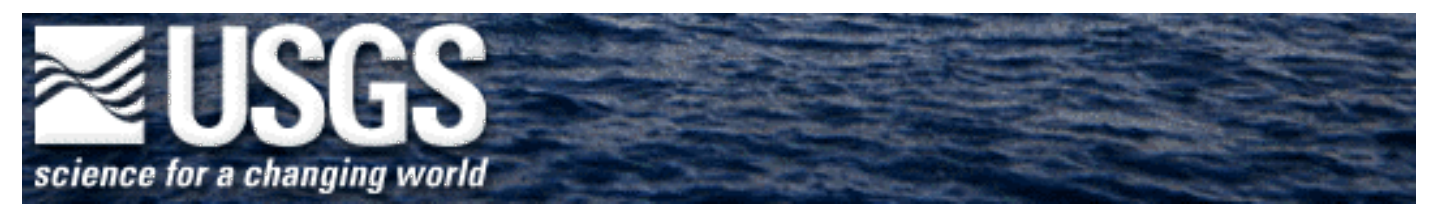

\title{
Digital Water-Quality Data Base for the West Branch Canal Creek Area, Aberdeen Proving Ground, Maryland
}

\author{
Authors: Vanessa C. Smith and Matthew G. Lesniewski, 2001 \\ Version 1.1
}

\begin{tabular}{|c|c|c|c|c|c|}
\hline$\frac{\text { View Readme }}{\text { File }}$ & $\underline{\text { Abstract }}$ & Introduction & ER Diagram & Tables & $\begin{array}{c}\text { Data } \\
\text { Dictionary }\end{array}$ \\
\hline
\end{tabular}

Digital Water-Quality Data Base

\begin{abstract}
This CD-ROM contains part of a data base that was developed by the U.S. Geological Survey (USGS) as part of a study in cooperation with the U.S. Army at West Branch Canal Creek, Aberdeen Proving Ground, Maryland. (Figure 1.) This part includes only selected data that were verified and approved for publication from November 1998 through September 1999. The data include descriptions and locations of sampling sites, field parameters measured, and the results of analyses for inorganic and organic constituents.
\end{abstract}

\section{Introduction}

The purpose of this data base is to store ground-water and surface-water data collected at West Branch Canal Creek, Aberdeen Proving Ground, Maryland. (Figure 2.) These data were collected in support of an ongoing USGS investigation of ground-water contamination in the wetland, including an evaluation of the factors controlling the fate and transport of the contaminants, and an analysis of natural attenuation as a possible remediation method. The data include descriptions and locations of sampling sites, field parameters measured, and the results of analyses for inorganic and organic constituents.

The user of the enclosed data base should be familiar with Microsoft Access and structured query language (SQL). This data base is structured in a relational data base data model with tables containing data in columns that fit into predefined categories. The data base structure is designed to support the ground-water-flow and solute-transport modeling of natural attenuation processes at Canal Creek. After meeting with the project staff, a set of basic criteria for inclusion in the data base was outlined. These were used as a starting point for the initial data base design. After further discussions, a final revised set of criteria was established. This set was then translated into an appropriate field and file structure for the data base.

\section{Entity Relationship Diagram of the Digital Water-Quality Data Base for the West Branch Canal Creek Area, Aberdeen Proving Ground, Maryland}

A full view of all the tables and fields in the data base and the overall structure of the data 
base is shown in an Entity Relationship Diagram included on this CD-ROM. This graphical representation of the data-base relationships is provided as an aid to understanding the structure of the data base. The diagram is comprised of three basic elements: entity types, attributes, and relationships. An entity is an object that stores data and is represented by rectangles on the diagram. The data base stores information about sampling locations, samples collected for analyses, results of analyses performed on each sample, and information about the various types of sampling locations. The entity information is called an attribute and is represented by ovals on the diagram. Each entity type in the data base has the same set of attributes with different attribute values. All tables are related to one another through defined relationships using the primary keys shown in diamonds on the diagram.

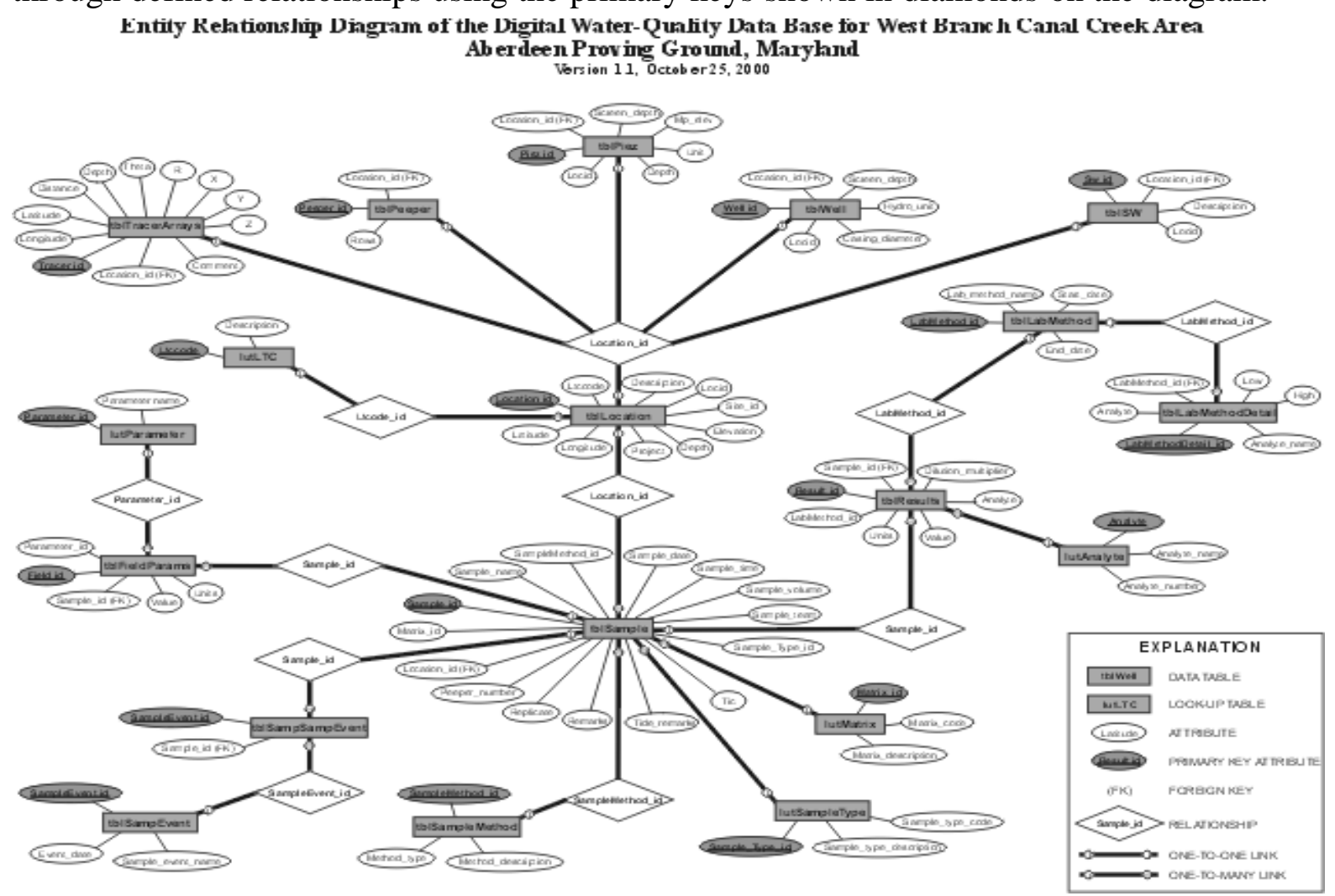

Figure 3. Entity relationship diagram of the digital water-quality data base (click to enlarge).

\section{Table Description}

Naming conventions are used for tables and fields. Names consist of whole words or phrases that describe the data contained in each table. All tables have a prefix of either "tbl" for basic data tables or "lut" for lookup tables, which are used to classify or quantify information in a data table. For example, "tblSample" is a table that contains basic data on samples, such as collection date and time, sample matrix, and sample location. The table "lutSampleType" is a lookup table that defines the type of sample that was collected such as a replicate or duplicate sample.

Every table in the data base has a field or a combination of fields that uniquely identifies each record in the table. This unique identifier is called the primary key and is labeled (PK) in the data dictionary. Primary keys have an "_id" suffix. For example, the location_id field in the location table is the primary key for that table; no two records in the location table have the same value in the location_id field. This provides a method to identify one particular record in the table. When a field in one table matches the primary key of another table, this is referred to as a foreign key (FK). Foreign keys are labeled (FK) in the data dictionary. For example, the location_id field in the sample table is a foreign key in that table. The location_id field links the location table and the sample table. 
Each row in a data table contains unique data for the categories defined by the columns. For example, the location table describes sampling locations with columns for latitude, longitude, elevation, and so forth. The sample table describes the samples that were collected with columns for data such as sample date, sample method, sample matrix, and location. By linking the sample and location tables, the user can view data on both the sample and the location where the sample was collected.

\section{Data Dictionary}

A Data Dictionary is provided to explain the layout of the data base. Instructions explaning how to read the data dictionary listings are also included. The data dictionary provides information on each table in the data base, including the table name, the number of fields and records, and the date and time the table was last updated. The tables are described in terms of the fields they contain, including field name, a brief description of the information in the field, and the type and size of the field.

\section{Digital Water-Quality Data Base}

\section{References}

Lorah, M.M., and Clark, J.S., 1996, Contamination of ground water, surface water, and soil, and evaluation of selected ground-water pumping alternatives in the Canal Creek Area of Aberdeen Proving Ground, Maryland: U.S. Geological Survey Open-File Report 95-282, $318 \mathrm{p}$.

Lorah, M.M., Olsen, L.D., Smith, B.A., Johnson, M.A., and Fleck, W.B., 1997, Natural attenuation of chlorinated volatile organic compounds in a freshwater tidal wetland, Aberdeen Proving Ground, Maryland: U.S. Geological Survey Water-Resources Investigations Report 97-4171, 95 p.

\section{Alternate Formats}

For your convenience, this report is provided in alternate formats on this CD-ROM. When printing pdf documents, be sure to select the "fit to page" option in your print menu.

Adobe Acrobat (PDF):

Introduction | Figure 1 | Figure 2 | Entity Relationship Diagram

Microsoft Word:

Introduction | Data Dictionary

Other Documents (ASCII Text):

Readme File | Disclaimer

For Comments or questions contact vcsmith@usgs.gov

Last Modified: Fri January 26, 10:27 EST 2001

Pages designed by Matthew Lesniewski 


\section{U.S. GEOLOGICAL SURVEY}

Digital Water-Quality Data Base for the West Branch Canal Creek

Area, Aberdeen Proving Ground, Maryland

Open-File Report 01-63

[ This File is the 1_README.TXT file. ]

Please read this document first before viewing the contents of this CD-ROM.

INTRODUCTION:

This Compact Disc (CD-ROM) contains U.S. Geological Survey (USGS) Open-File Report 01-63, titled "Digital Water-Quality Data Base for the West Branch Canal Creek Area, Aberdeen Proving Ground, Maryland," by Vanessa C. Smith and Matthew G. Lesniewski.

This CD-ROM contains part of a data base that was developed by the U.S. Geological Survey as part of a study in cooperation with the U.S. Army at West Branch Canal Creek, Aberdeen Proving Ground, Maryland. This part includes only selected data from November 30, 1998 to September 30, 1999 that were verified and approved for publication.

The contents of this report and CD-ROM have been approved for public release and unlimited distribution by the U.S. Army -- Distribution Number 3723-A-6.

\section{THIS CD-ROM MAY BE OBTAINED FROM:}

U.S. Geological Survey

8987 Yellow Brick Road

Baltimore, Maryland 21237

Telephone: (410) 238-4200

email: GS-W-MDtws_DC@usgs.gov

http://md.water.usgs.gov/

OR

U.S. Geological Survey

Information Services, National Mapping Division

Box 25046

Denver Federal Center

Denver, CO 80225-0046

Telephone: (888) ASK-USGS 
TO GET STARTED:

The file "INDEX.HTM" must be loaded into any web browser to begin viewing the CD.

On a Windows 95/98/NT PC, the "INDEX.HTM" should automatically load into Netscape (r) or Internet Explorer (r) when you insert the CD-ROM. If it does not auto-open, open your CD-ROM drive under "My Computer" and doubleclick on the file "INDEX.HTM" to open this in your default web browser.

On a Macintosh, double-click on the CD-ROM icon and double-click on the file "INDEX.HTM" to open the CD-ROM in your default web browser.

Some links included on this CD-ROM may lead to Web pages at several internet locations. Users must have internet access to retrieve these pages. These internet locations may change during the useful lifetime of this CD-ROM; therefore, users may have difficulty reaching the external pages, even with an internet connection.

\section{REQUIRED SOFTWARE:}

\section{MICROSOFT ACCESS (r)}

The Digital Water-Quality Data Base can be viewed using Microsoft Access 2000 (r) or later. Access 2000 (r) is only available for computers with the Microsoft Windows (r) operating system. For more information about Microsoft Access 2000 (r), please see http://www.microsoft.com/office/

\section{ADOBE ACROBAT READER (r)}

The ACROBAT directory on this CD-ROM contains English language installers for Adobe Acrobat Reader for both Windows and Macintosh. For more information about Adobe Acrobat, or for other languages or versions, please see the Adobe Acrobat Reader web page at http://www.adobe.com/products/acrobat/readstep.html

For Windows NT and Windows 95/98, a 32-bit version (RS405ENG.EXE) is provided. A 16-bit version (RS16E301.EXE) is provided for Windows 3.1. For Macintosh, a PowerPC version (RS405ENG.HQX) is provided.

("(r)" denotes a registered trademark.)

\section{INFORMATION FOR THE VISUALLY IMPAIRED:}

Adobe has information about PDF and the visually challenged. This information provides tools to help make PDF files accessible to the visually disabled. These tools convert Adobe PDF documents into HTML or 
ASCII text which can then be read by a number of common screen reading programs that synthesize text as audible speech. These tools may be obtained free of charge from Adobe at URL: http://access.adobe.com/

\section{DISC INFORMATION:}

This disc complies with ISO 9660 Level 1 standard for CD-ROM's. The intended use is with personal computers and the Windows operating system. The disc is compatible with UNIX, Macintosh, and other computers equipped with the appropriate CD-ROM reader and software.

The overall layout of the disc is as follows:

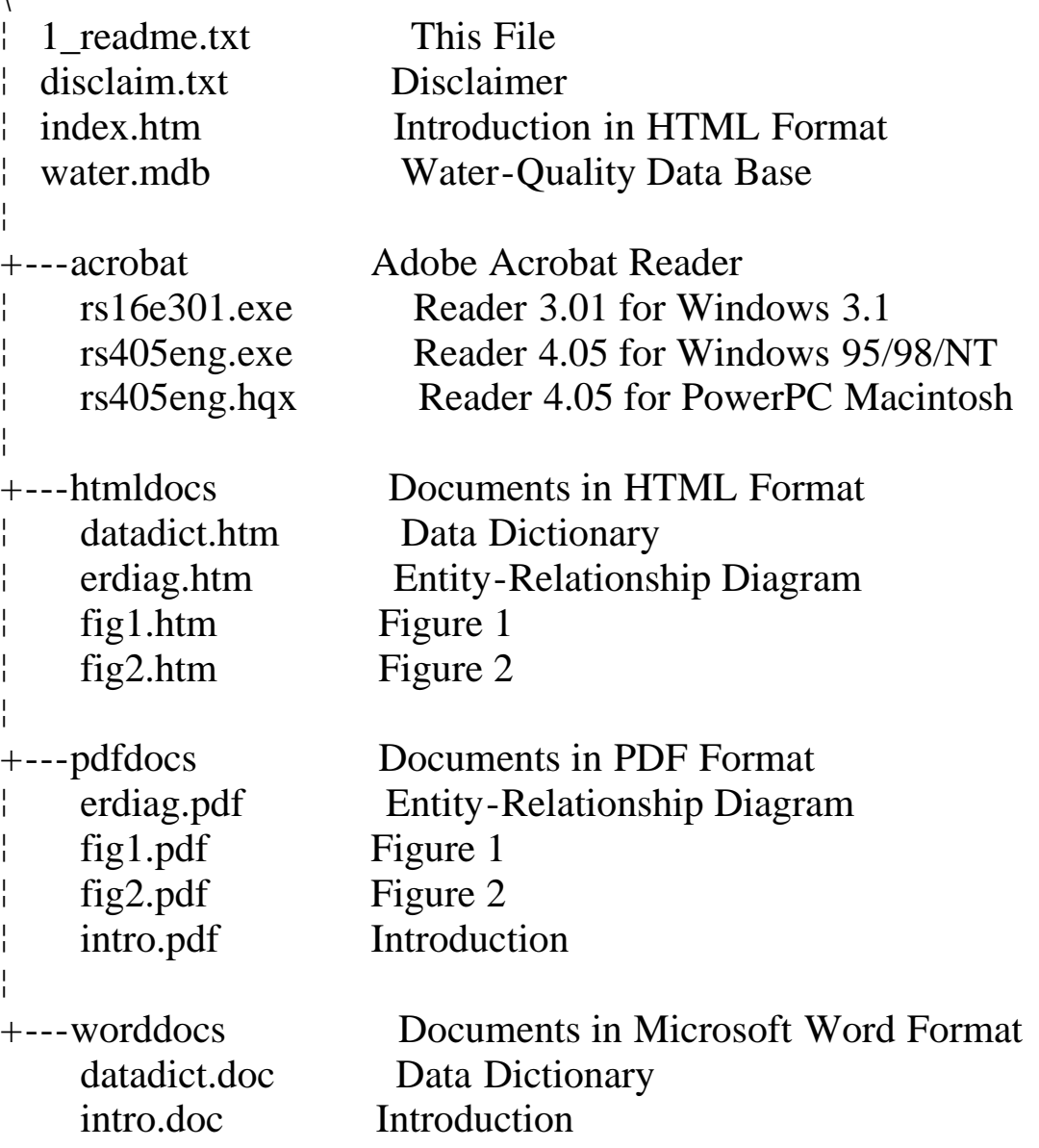

(Note: Only files related to this report are listed. Support files are not displayed in this list.)

For additional information, contact:

District Chief

U.S. Geological Survey

8987 Yellow Brick Road

Baltimore, Maryland 21237 
Telephone: (410) 238-4200

email: GS-W-MDtws_DC@usgs.gov

http://md.water.usgs.gov/ 


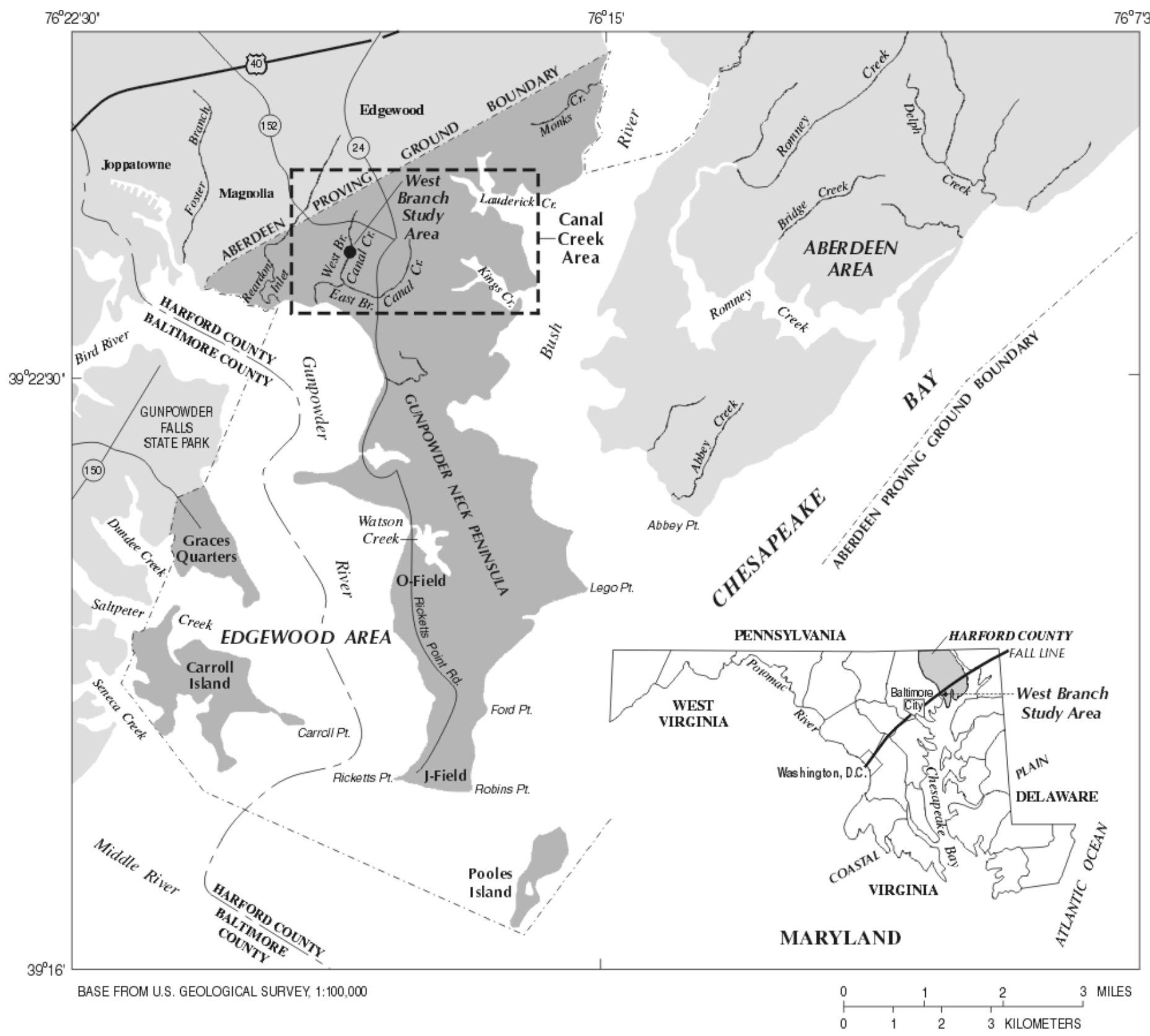

Figure 1. Location of Canal Creek area and West Branch study area, Aberdeen Proving Ground, Maryland (modified from Lorah and others, 1997, p. 5). 


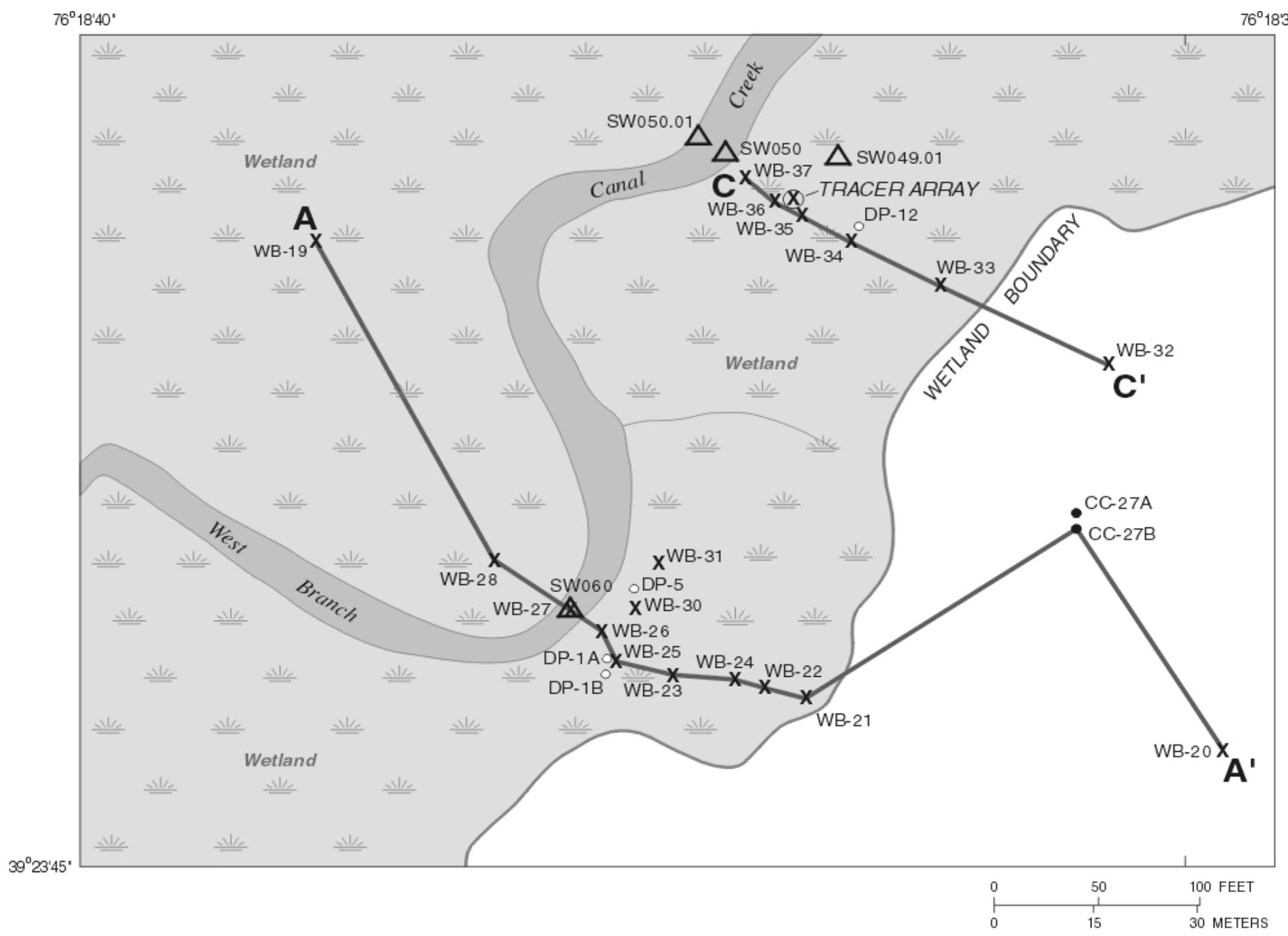

EXPLANATION

- 4 4" WELL FROM PREVIOUS STUDY

- 2" PIEZOMETER SITE

A-A' LINE OF SECTION
X $\quad 0.75$-INCH PIEZOMETER SITE

$\boldsymbol{\otimes}$ TRACER aRray

SW060 $\triangle$ SURFACE-WATER SITE AND

$\begin{array}{cl}\text { CC-27A } & \text { WELL OR PIEZOMETER } \\ \text { DP-12 } & \text { SITE NUMBER } \\ \text { WB-20 } & \end{array}$

Figure 2. Locations of sampling sites and transects $A-A^{\prime}$ and $C-C^{\prime}$ in the wetland study area along West Branch Canal Creek, Aberdeen Proving Ground, Maryland (modified from Lorah and Clark, 1996, p. 106). 
Entity Relationship Diagram of the Digital Water-Quality Data Base for West Branch Canal Creek Area Aberdeen Proving Ground, Maryland

Version 1.1, October 25, 2000

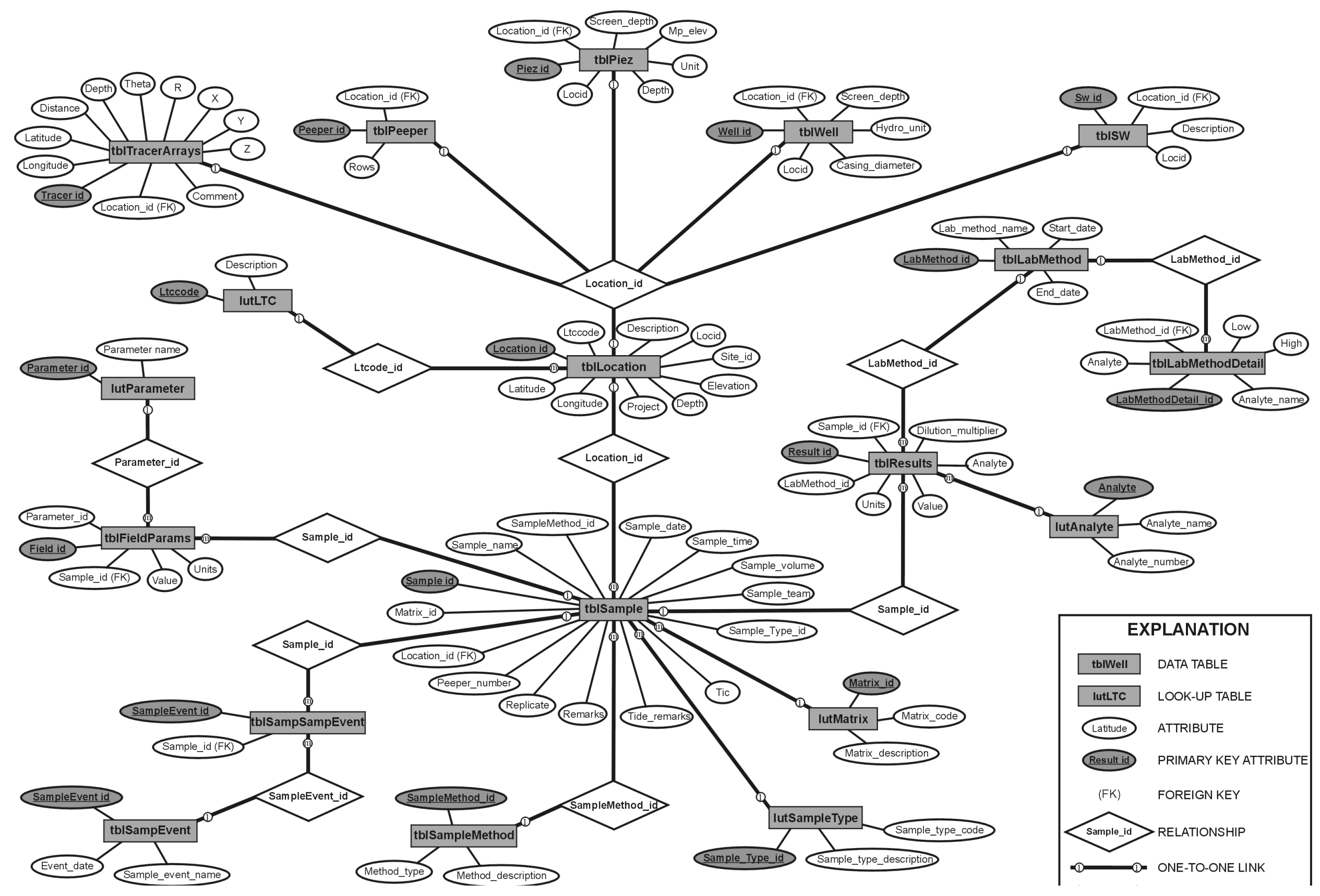


Figure 3. Entity Relation Diagram for Digital Water Quality Database 


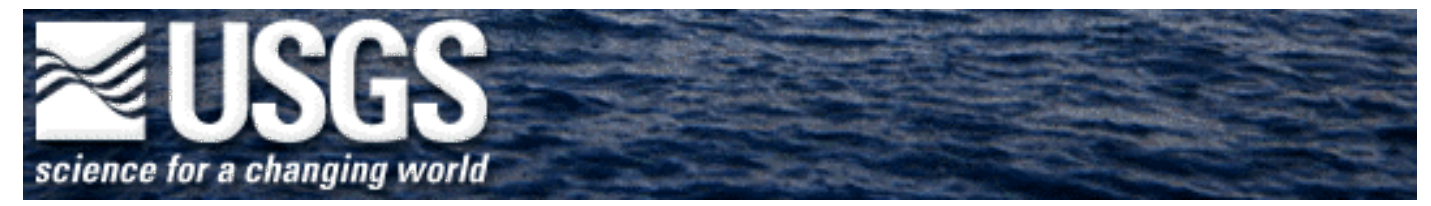

\title{
Digital Water-Quality Data Base for the West Branch Canal Creek Area, Aberdeen Proving Ground, Maryland
}

\author{
Authors: Vanessa C. Smith and Matthew G. Lesniewski, 2001 \\ Version 1.1
}

\section{Digital Water-Quality Data Base}

\section{Data Dictionary}

\section{How to read the Data Dictionary listings:}

The description of each table begins with the header information:

Table name.

Number of fields.

Number of records at the time the dictionary was generated.

Date of last update to the table.

Description of the table contents.

The tables are listed in alphabetical order starting with the look-up tables.

Below each Table description, definition information is presented for each field in the table, including the following attributes:

Field position (order number) within the table.

\section{Field name}

PK Fields that uniquely identify each record in a table (checked if field is part of the Primary Key for the table).

FK Fields that obtain their value from another table (checked if field is a Foreign Key).

Rqd (checked if field is Required to have a value for each record in the table; if unchecked, field is optional).

Data type of the field.

Size of the field (allowed number of characters for Text fields; for other data types it represents the number of bytes used for storage).

Default value for the field (usually refers to a Foreign Key value representing a selection from a domain table).

Description of the field

\section{List of Tables contained within the Data Base:}




\begin{tabular}{||l||l||l||l||}
\hline Table Name & Fields & Records & Date and Time \\
\hline lutAnalyte & 3 & 85 & $9 / 19 / 2000$ 8:45 \\
\hline \hline
\end{tabular}

Table description: The lutAnalyte table stores the name and abbreviated code representing an analyte.

\begin{tabular}{|l||l|l|l|l|l|l|l|l||}
\hline Field Name & PK & FK & Rqd & \multicolumn{1}{|c|}{ Type } & Size & Default & \multicolumn{1}{|c||}{ Description } \\
\hline 1 Analyte & $\mathbf{V}$ & & $\mathbf{V}$ & Text & 50 & & $\begin{array}{l}\text { Abbreviated code representing } \\
\text { analyte }\end{array}$ \\
\hline 2 Analyte_name & & & & Text & 50 & & Name of analyte \\
\hline 3 Analyte_number & & & Number(Long) & 4 & 0 & $\begin{array}{l}\text { Numerical code from purge-and- } \\
\text { trap gas chromatograph with } \\
\text { mass-selective detector } \\
\text { GC/MSD) identifying the } \\
\text { analyte }\end{array}$ \\
\hline
\end{tabular}

\begin{tabular}{|l||l||l|l||}
\hline Table Name & Fields & Records & Date and Time \\
\hline lutLTC & 2 & 7 & $9 / 19 / 2000$ 8:45 \\
\hline
\end{tabular}

Table description:The lutLTC table stores the code name and description of the sampling location type and is referenced by the location table.

\begin{tabular}{|c|c|c|c|c|c|c|c|}
\hline Field Name & PK & FK & Rqd & Type & Size & Default & Description \\
\hline 1 Ltccode & $\square$ & & $\square$ & Text & 50 & & Unique code used to identify the location type \\
\hline 2 Description & & & & Text & 50 & & $\begin{array}{l}\text { Description of the location type } \\
\text { Domain options: } \\
\text { HP - Hoverprobe } \\
\text { LB - Lab sample } \\
\text { PP - Peeper } \\
\text { PZ - Piezometer } \\
\text { SW - Surface water } \\
\text { TA - Tracer array } \\
\text { WL - Well }\end{array}$ \\
\hline
\end{tabular}

\begin{tabular}{|l||l|l|l||}
\hline Table Name & Fields & Records & Date and Time \\
\hline lutMatrix & 3 & 4 & $9 / 19 / 2000$ 8:45 \\
\hline
\end{tabular}

Table description:The lutMatrix table stores the code name and description of the sampling medium collected for analysis and is referenced by tblSample table.

\begin{tabular}{|l||l|l|l|l||l|l|l||}
\hline Field Name & PK & FK & Rqd & \multicolumn{1}{|c|}{ Type } & Size & Default & \multicolumn{1}{|c||}{ Description } \\
\hline 1 Matrix_id & V & & V & Number(Long) & 4 & 0 & Matrix identifier \\
\hline 2 Matrix_code & & & & Text & 50 & & $\begin{array}{l}\text { Unique code assigned to } \\
\text { matrix }\end{array}$ \\
\hline 3 Matrix_description & & & & Text & 50 & & $\begin{array}{l}\text { Description of sampling } \\
\text { medium collected for analysis }\end{array}$ \\
& & & & & & &
\end{tabular}




$\|\quad\| \quad \| \quad \begin{aligned} & \text { Domain options: } \\ & \text { WG - Ground water } \\ & \text { WQ - Water quality } \\ & \text { WS - Surface water }\end{aligned}$

\begin{tabular}{|l||l|l||l||}
\hline Table Name & Fields & Records & Date and Time \\
\hline lutParameter & 2 & 15 & $9 / 19 / 20008: 45$ \\
\hline
\end{tabular}

Table description:The lutParameter table stores the parameter name of field parameters and is referenced by the tblFieldParams table.

\begin{tabular}{|l|l|l|l|l||l|l||l||}
\hline Field Name & PK & FK & Rqd & \multicolumn{1}{|c|}{ Type } & Size & Default & \multicolumn{1}{|c|}{ Description } \\
\hline 1 Parameter_id & $\square$ & & $\square$ & Number(Long) & 4 & 0 & Parameter identifier \\
\hline 2 Parameter_name & & & & Text & 50 & & Name of field parameter \\
\hline \hline
\end{tabular}

\begin{tabular}{|l||l|l|l||}
\hline Table Name & Fields & Records & Date and Time \\
\hline lutSampleMethod & 3 & 6 & $9 / 19 / 2000$ 8:45 \\
\hline \hline
\end{tabular}

Table description: The lutSampleMethod table stores the code and description of the method used to collect samples and is referenced by the tblSample.

\begin{tabular}{|c|c|c|c|c|c|c|c|}
\hline Field Name & PK & FK & Rqd & Type & Size & Default & Description \\
\hline 1 SampleMethod_id & $\nabla$ & & $\square$ & Number(Long) & 4 & 0 & Sample method identifier \\
\hline 2 Method_type & & & & Text & 50 & & $\begin{array}{l}\text { Unique code assigned to } \\
\text { sampling method }\end{array}$ \\
\hline 3 Method_description & & & & Text & 50 & & $\begin{array}{l}\text { Description of sampling } \\
\text { method used to collect the } \\
\text { sample } \\
\text { Domain options: } \\
\text { Sub - Submersible pump } \\
\text { Per - Peristaltic pump } \\
\text { Hand - Hand pump } \\
\text { Syr - Syringe } \\
\text { Bail - Bailer }\end{array}$ \\
\hline
\end{tabular}

\begin{tabular}{|l||l|l|l||}
\hline Table Name & Fields & Records & Date and Time \\
\hline lutSampleType & 3 & 3 & $9 / 19 / 20008: 45$ \\
\hline
\end{tabular}

Table description: The lutSample table stores the code and description of the type of sample collected and is referenced by the tblSample.

\begin{tabular}{||l||l|l|l|l|l|l||l||}
\hline Field Name & PK & FK & Rqd & Type & Size & Default & \multicolumn{1}{|c||}{ Description } \\
\hline 1 SampleType_id & - & & $\square$ & Number(Long) & 4 & 0 & Sample type identifier \\
\hline 2 Sample_type_code & & & & Text & 50 & & $\begin{array}{l}\text { Unique code assigned to } \\
\text { sample type }\end{array}$ \\
\hline & & & & & & & \\
\hline
\end{tabular}




\begin{tabular}{|c|c|c|c|}
\hline |3 Sample_type_description| & Text & $\mid 50$ & $\mid \begin{array}{l}\text { Description of sample } \\
\text { type collected } \\
\text { Domain options: } \\
\text { N - Normal sample } \\
\text { DUP - Duplicate sample } \\
\text { BL - Blank sample }\end{array}$ \\
\hline
\end{tabular}

\begin{tabular}{|l||l|l|l||}
\hline Table Name & Fields & Records & Date and Time \\
\hline lutUnits & 2 & 5 & $9 / 19 / 20008: 45$ \\
\hline
\end{tabular}

Table description: The lutUnits table stores codes for the units of measure used in the analyses of samples and is referenced by tblSample and tblFieldParams.

\begin{tabular}{|l||c|c|c|c||l|l|l||}
\hline Field Name & PK & FK & Rqd & \multicolumn{1}{|c|}{ Type } & Size & Default & \multicolumn{1}{|c|}{ Description } \\
\hline 1 Units_id & $\square$ & & $\square$ & Number(Long) & 4 & 0 & Units identifier \\
\hline 2 Units & & & & Text & 50 & & Unit of measure \\
\hline \hline
\end{tabular}

\begin{tabular}{|l||l|l|l|}
\hline Table Name & Fields & Records & Date and Time \\
\hline tblFieldParams & 6 & 143 & $9 / 19 / 20008: 45$ \\
\hline
\end{tabular}

Table description: The tblFieldParams table stores information and results for field parameters

\begin{tabular}{|c|c|c|c|c|c|c|c|}
\hline Field Name & PK & FK & Rqd & Type & Size & Default & Description \\
\hline 1 Field_id & $\square$ & & $\square$ & Auto Number(Long) & 4 & 0 & Field sample identifier \\
\hline 2 Sample_id & & $\square$ & & Number(Long) & 4 & 0 & Identifier of sample \\
\hline 3 Location_id & & $\square$ & & Number(Long) & 4 & 0 & Identifier of location \\
\hline 4 Parameter_id & & $\bar{\square}$ & & Number(Long) & 4 & 0 & Identifier of parameter \\
\hline 5 Value & & & & Text & 50 & & Analytical value \\
\hline 6 Units & & & & Text & 50 & & Measurement unit \\
\hline
\end{tabular}

\begin{tabular}{|l||l|l|l||}
\hline Table Name & Fields & Records & Date and Time \\
\hline tblLabMethod & 4 & 18 & $9 / 19 / 20008: 45$ \\
\hline
\end{tabular}

Table description: The tblLabMethod table stores information on the lab method used on samples analyzed using the GC/MSD purge-and-trap gas chromatograph with mass-selective detector and the dates the method was applied.

\begin{tabular}{|l|l|l|l||l||l|l||l||}
\hline Field Name & PK & FK & Rqd & \multicolumn{1}{|c|}{ Type } & Size & Default & \multicolumn{1}{|c|}{ Description } \\
\hline 1 LabMethod_id & $\nabla$ & & $\square$ & Auto Number(Long) & 4 & & Lab method identifier \\
\hline 2 Lab_method_name & & & & Text & 255 & & Name of lab method \\
\hline 3 Start_date & & & & Date/Time & 8 & & Start date of lab method \\
\hline \hline 4 End_date & & & & Date/Time & 8 & & End date of lab method \\
\hline
\end{tabular}




\begin{tabular}{|l||l|l|l|}
\hline Table Name & Fields & Records & Date and Time \\
\hline tblLabMethodDetail & 6 & 1152 & $9 / 19 / 2000$ 8:45 \\
\hline \hline
\end{tabular}

Table description: The tblLabMethodDetail table stores information on the concentration of the lowest and highest calibration standard (upper and lower reporting limit) for each parameter in the lab method.

\begin{tabular}{|c|c|c|c|c|c|c|c|}
\hline Field Name & PK & FK & Rqd & Type & Size & Default & Description \\
\hline 1 LabMethodDetail_id & $\nabla$ & & $\square$ & $\begin{array}{l}\text { Auto } \\
\text { Number(Long) }\end{array}$ & 4 & & $\begin{array}{l}\text { Lab method detail } \\
\text { identifier }\end{array}$ \\
\hline 2 LabMethod_id & & $\square$ & & Number(Long) & 4 & 0 & Identifier of lab method \\
\hline 3 Analyte_name & & & & Text & 255 & & Long name of analyte \\
\hline 4 Analyte & & & & Text & 50 & & Short name of analyte \\
\hline 5 Low & & & & Number(Double) & 8 & & $\begin{array}{l}\text { Concentration of the lowest } \\
\text { calibration standard (lower } \\
\text { reporting limit) }\end{array}$ \\
\hline 6 High & & & & Number(Double) & 8 & & $\begin{array}{l}\text { Concentration of the } \\
\text { highest calibration standard } \\
\text { (upper reporting limit) }\end{array}$ \\
\hline
\end{tabular}

\begin{tabular}{|l||l|l||l|}
\hline Table Name & Fields & Records & Date and Time \\
\hline tblLocation & 10 & 353 & $9 / 19 / 20008: 45$ \\
\hline
\end{tabular}

Table description: The tblLocation stores information on sampling locations.

\begin{tabular}{|c|c|c|c|c|c|c|c|}
\hline Field Name & PK 1 & FK & Rqd & Type & Size & Default & Description \\
\hline 1 Location_id & $\nabla$ & & $\square$ & \begin{tabular}{|l|} 
Auto \\
Number(Long)
\end{tabular} & 4 & & Location identifier \\
\hline 2 Locid & & & & Text & 15 & & $\begin{array}{l}\text { Location name assigned to the } \\
\text { location where samples or } \\
\text { measurements are collected }\end{array}$ \\
\hline 3 Ltccode & & $\bar{\nabla}$ & & Text & 2 & & $\begin{array}{l}\text { Coded value describing location } \\
\text { where samples or measurements are } \\
\text { taken }\end{array}$ \\
\hline 4 Site_id & & & & Text & 255 & Null & USGS site identification \\
\hline 5 Latitude & & & & Text & 15 & & Latitude of location \\
\hline 6 Longitude & & & & Text & 15 & & Longitude of location \\
\hline 7 Elevation & & & & Text & 8 & & $\begin{array}{l}\text { Elevation of ground surface at } \\
\text { sampling location }\end{array}$ \\
\hline 8 Depth & & & & Text & 8 & & $\begin{array}{l}\text { Total depth of sampling location, } \\
\text { measured in feet relative to ground }\end{array}$ \\
\hline 9 Project & & & & Text & 50 & & Project area of location \\
\hline 10 Description & & & & Text & 50 & & Description of location \\
\hline
\end{tabular}




\begin{tabular}{||l||l||l||l||}
\hline Table Name & Fields & Records & Date and Time \\
\hline tblPeeper & 3 & 3 & $9 / 19 / 2000$ 8:45 \\
\hline
\end{tabular}

Table description: The tblPeeper table stores information on peepers used to collect samples.

\begin{tabular}{|l||l|l|l|l|l|l|l|l||}
\hline Field Name & PK & FK & Rqd & \multicolumn{1}{|c|}{ Type } & Size & Default & \multicolumn{1}{|c|}{ Description } \\
\hline 1 Peeper_id & $\square$ & & $\square$ & Number(Long) & 4 & 0 & Peeper site identifier \\
\hline 2 Location_id & & $\square$ & & Number(Long) & 4 & 0 & Identifier of location \\
\hline 3 Rows & & & & Number(Long) & 4 & 0 & Number of rows in peeper \\
\hline
\end{tabular}

\begin{tabular}{|l||l|l|l||}
\hline Table Name & Fields & Records & Date and Time \\
\hline \hline tblPiez & 7 & 78 & $9 / 19 / 2000$ 8:45 \\
\hline
\end{tabular}

Table description: The tblPiez table stores information on piezometers used to collect samples.

\begin{tabular}{|l||l|l|l|l|l|l|l||}
\hline Field Name & PK & FK & Rqd & \multicolumn{1}{|c|}{ Type } & Size & Default & \multicolumn{1}{|c||}{ Description } \\
\hline 1 Piez_id & - & & $\square$ & Number(Long) & 4 & 0 & Piezometer identifier \\
\hline 2 Location_id & & $\square$ & & Number(Long) & 4 & 0 & Identifier of location \\
\hline 3 Locid & & & & Text & 255 & & Unique name given to piezometer \\
\hline 4 Unit & & & & Text & 255 & & Hydrogeologic unit \\
\hline 5 Screen_depth & & & & Text & 255 & & Depth of screen (in feet) \\
\hline 6 Depth & & & Number(Double) & 8 & & Total depth \\
\hline 7 Mp_elevation & & & Number(Double) & 8 & & $\begin{array}{l}\text { Measuring-point elevation of } \\
\text { piezometer measured in feet, } \\
\text { relative to ground surface }\end{array}$ \\
\hline
\end{tabular}

\begin{tabular}{|l||l|l|l||}
\hline Table Name & Fields & Records & Date and Time \\
\hline tblResults & 7 & 12540 & $9 / 19 / 2000$ 8:45 \\
\hline
\end{tabular}

Table description: The tblResults table stores information on the analytical results of a sampling test procedure.

\begin{tabular}{|c|c|c|c|c|c|c|c|}
\hline Field Name & PK & FK & Rqd & Type & Size & Default & Description \\
\hline 1 Result_id & $\nabla$ & & $\nabla$ & Number(Long) & 4 & 0 & Result identifier \\
\hline 2 Sample_id & & $\square$ & & \begin{tabular}{|l|} 
Number(Long) \\
\end{tabular} & 4 & 0 & Identifier of sample \\
\hline 3 Analyte & & & & \begin{tabular}{|l|} 
Text \\
\end{tabular} & 50 & & Name of compound analyzed \\
\hline 4 Value & & & & Text & 50 & & Value of analyte \\
\hline 5 Units & & & & Text & 50 & & Unit of measure \\
\hline 6 Dilution_multiplier & & & & Text & 50 & & $\begin{array}{l}\text { Dilution multiplier used for the } \\
\text { sample }\end{array}$ \\
\hline 7 LabMethod_id & & $\square$ & & Number(Long) & 4 & 0 & Identifier of lab method \\
\hline
\end{tabular}




\begin{tabular}{||l||l||l||l||} 
Table Name & Fields & Records & Date and Time \\
\hline tblSampEvent & 3 & 10 & $9 / 19 / 20008: 45$ \\
\hline \hline
\end{tabular}

Table description: The tblSampEvent table stores information on a sampling event

\begin{tabular}{|l|l|l|l|l|l|l|l||}
\hline Field Name & PK & FK & Rqd & \multicolumn{1}{|c|}{ Type } & Size & Default & \multicolumn{1}{|c||}{ Description } \\
\hline 1 SampleEvent_id & $\square$ & & $\square$ & Number(Long) & 4 & 0 & Sample event identifier \\
\hline 2 Sample_event_name & & & & Text & 50 & & Name of sampling event \\
\hline 3 Event_date & & & & Text & 50 & & Date/dates of sampling event \\
\hline
\end{tabular}

\begin{tabular}{|l||l|l|l||}
\hline Table Name & Fields & Records & Date and Time \\
\hline tblSample & 15 & 459 & $9 / 19 / 20008: 45$ \\
\hline
\end{tabular}

Table description: The tblSample table stores information on samples collected for analysis.

\begin{tabular}{|c|c|c|c|c|c|c|c|}
\hline Field Name & PK & FK & Rqd & Type & Size & Default & Description \\
\hline 1 Sample_id & $\nabla$ & & $\square$ & Number(Long) & 4 & 0 & Sample identifier \\
\hline 2 Sample_name & & & & Text & 50 & & Name given to sample \\
\hline 3 Location_id & & $\square$ & & Number(Long) & 4 & 0 & $\begin{array}{l}\text { Identifier of location where } \\
\text { sample was collected }\end{array}$ \\
\hline 4 SampleType_id & & $\square$ & & Number(Long) & 4 & 0 & Identifier of the sample type \\
\hline 5 Sample_volume & & & & Number(Long) & 4 & 0 & Volume of sample \\
\hline 6 Replicate & & & & Text & 50 & & Replicate number of the sample \\
\hline 7 Sample_date & & & & Date/Time & 8 & & Date sample was collected \\
\hline 8 Sample_time & & & & \begin{tabular}{|l|} 
Date/Time \\
\end{tabular} & 8 & & Time sample was collected \\
\hline 9 SampleMethod_id & & $\square$ & & Number(Long) & 4 & 0 & $\begin{array}{l}\text { Identifier of the sampling } \\
\text { method }\end{array}$ \\
\hline 10 Matrix_id & & $\square$ & & Text & 50 & & Identifier of sample matrix \\
\hline 11 Tic & & & & Text & 50 & & $\begin{array}{l}\text { Tentatively identified } \\
\text { compound found in sample }\end{array}$ \\
\hline 12 Peeper_number & & & & Number(Long) & 4 & 0 & $\begin{array}{l}\text { Peeper cell number from which } \\
\text { the sample was collected }\end{array}$ \\
\hline 13 Tide_remarks & & & & Text & 150 & & $\begin{array}{l}\text { Tide at the time sample was } \\
\text { taken }\end{array}$ \\
\hline 14 Remarks & & & & Text & 255 & & Remarks on the sample \\
\hline 15 Sample_team & & & & Text & 50 & & Sampling team \\
\hline
\end{tabular}

\begin{tabular}{|l||l|l|l||}
\hline Table Name & Fields & Records & Date and Time \\
\hline tblSampSampEvent & 2 & 443 & $9 / 19 / 2000$ 8:45 \\
\hline \hline
\end{tabular}

Table description: The tblSampSampEvent stores the sample event associated with each sample

\begin{tabular}{|l|l|l|l|l|l|l||l|}
\hline Field Name & PK & FK & Rqd & Type & Size & Default & Description \\
\hline \hline
\end{tabular}




\begin{tabular}{||l||l||l||l||l||l||l||l||} 
1 SampleEvent_id & $\square$ & $\square$ & $\square$ & Number(Long) & 4 & 0 & Sample event identifier \\
\hline 2 Sample_id & $\square$ & $\square$ & $\square$ & Number(Long) & 4 & 0 & Identifier of sample \\
\hline \hline
\end{tabular}

\begin{tabular}{|l||l||l|l|}
\hline Table Name & Fields & Records & Date and Time \\
\hline tblSW & 4 & 5 & $9 / 19 / 20008: 45$ \\
\hline
\end{tabular}

Table description: The tblSW stores general information on surface-water sampling sites

\begin{tabular}{|l|l|l|l|l|l|l|l||}
\hline Field Name & PK & FK & Rqd & \multicolumn{1}{|c|}{ Type } & Size & Default & \multicolumn{1}{|c||}{ Description } \\
\hline 1 SW_id & $\nabla$ & & $\square$ & Number(Long) & 4 & 0 & Surface-water identifier \\
\hline 2 Location_id & & $\nabla$ & & Number(Long) & 4 & 0 & Identifier of location \\
\hline 3 Locid & & & & Text & 50 & & Site name \\
\hline \hline 4 Description & & & & Text & 50 & & Description of location \\
\hline
\end{tabular}

\begin{tabular}{|l||l|l|l|}
\hline Table Name & Fields & Records & Date and Time \\
\hline tblTracerArrays & 12 & 100 & $9 / 19 / 20008: 45$ \\
\hline
\end{tabular}

Table description: The tblTracerArrays stores general information on tracer array sampling locations

\begin{tabular}{|c|c|c|c|c|c|c|c|}
\hline Field Name & PK & FK & Rqd & Type & Size & Default & Description \\
\hline 1 Tracer_id & $\nabla$ & & $\square$ & \begin{tabular}{|l} 
Auto \\
Number(Long)
\end{tabular} & 4 & & Tracer array identifier \\
\hline 2 Location_id & & $\square$ & & Number(Long) & 4 & 0 & $\begin{array}{l}\text { Location identifier perpendicular to } \\
\text { the creek (in inches) }\end{array}$ \\
\hline $3 \mathrm{X}$ & & & & Number(Double) & 8 & & $\begin{array}{l}\text { Rectilinear coordinate perpendicular } \\
\text { to the creek (in inches) }\end{array}$ \\
\hline $4 \mathrm{Y}$ & & & & Number(Double) & 8 & & $\begin{array}{l}\text { Rectilinear coordinate parallel to the } \\
\text { creek (in inches) }\end{array}$ \\
\hline $5 \mathrm{Z}$ & & & & Number(Double) & 8 & & $\begin{array}{l}\text { Vertical distance from the injection } \\
\text { point (in inches) }\end{array}$ \\
\hline 6 Theta & & & & Number(Double) & 8 & & $\begin{array}{l}\text { Angular coordinate in the radial } \\
\text { direction }\end{array}$ \\
\hline $7 \mathrm{R}$ & & & & Number(Double) & 8 & & $\begin{array}{l}\text { Radial distance from the origin in } \\
\text { the radial coordinate system }\end{array}$ \\
\hline 8 Latitude & & & & Number(Long) & 4 & 0 & Latitude of tracer array \\
\hline 9 Longitude & & & & Number(Long) & 4 & 0 & Longitude of tracer array \\
\hline 10 Comment & & & & Text & 50 & & Comment regarding tracer array \\
\hline 11 Depth & & & & Number(Double) & 8 & & $\begin{array}{l}\text { Vertical distance from land surface } \\
\text { to the piezometer opening (in } \\
\text { inches) }\end{array}$ \\
\hline 12 Distance & & & & Number(Double) & 8 & 0 & $\begin{array}{l}\text { Linear distance from the tracer } \\
\text { injection point to the piezometer } \\
\text { measuring point (in inches) }\end{array}$ \\
\hline
\end{tabular}




\begin{tabular}{|l|l|l|l|}
\hline Table Name & Fields & Records & Date and Time \\
\hline tblWell & 6 & 124 & $9 / 19 / 2000$ 8:45 \\
\hline
\end{tabular}

Table description: The tblWell table stores general information on wells.

\begin{tabular}{|c|c|c|c|c|c|c|c|}
\hline Field Name & PK & FK & Rqd & Type & Size & Default & Description \\
\hline 1 Well_id & $\square$ & & $\square$ & Auto Number(Long) & 4 & & Well identifier \\
\hline 2 Location_id & & $\square$ & & Number(Long) & 4 & 0 & Identifier of location \\
\hline 3 Locid & & & & Text & 50 & & Name of well \\
\hline 4 Casing_diameter & & & & Number(Double) & 8 & & Diameter of well (in inches) \\
\hline 5 Screen_depth & & & & Text & 50 & & Depth of screen (in feet) \\
\hline 6 Hydro_unit & & & & Text & 50 & & Hydrogeomorphic unit \\
\hline
\end{tabular}

\section{Summary Count of Table and Fields:}

\section{Table and Field Listing}

\begin{tabular}{|r|l|}
\hline Number of Tables & 20 \\
\hline \hline Total Number of Fields & 103 \\
\hline \hline Unique Key Fields & 37 \\
\hline \hline Non-Key Fields & 66 \\
\hline Total Number of Records & 15,553 \\
\hline
\end{tabular}

For Comments or questions contact vcsmith@usgs.gov

Last Modified: Fri Feb 23, 10:31 EST 2001

Pages designed by Matthew Lesniewski 


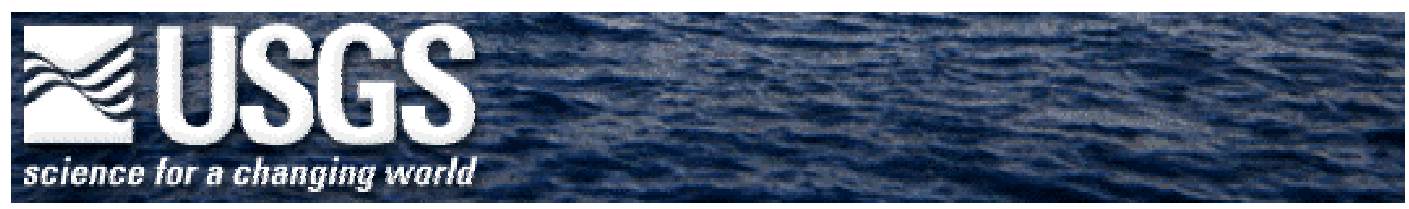

\title{
Digital Water-Quality Data Base for the West Branch Canal Creek Area, Aberdeen Proving Ground, Maryland \\ Authors: Vanessa C. Smith and Matthew G. Lesniewski, 2001
}

Version 1.1

\begin{abstract}
This CD-ROM contains part of a data base that was developed by the U.S. Geological Survey (USGS) as part of a study in cooperation with the U.S. Army at West Branch Canal Creek, Aberdeen Proving Ground, Maryland. This part includes only selected data from November 1998 through September 1999 that were verified and approved for publication. The data include descriptions and locations of sampling sites, field parameters measured, and the results of analyses for inorganic and organic constituents

\section{Introduction}

The purpose of this data base is to store ground-water and surface-water data collected at West Branch Canal Creek, Aberdeen Proving Ground, Maryland. These data were collected in support of an ongoing USGS investigation of ground-water contamination in a wetland, including an evaluation of the factors controlling the fate and transport of the contaminants, and an analysis of natural attenuation as a possible remediation method. The data include descriptions and locations of sampling sites, field parameters measured, and the results of analyses for inorganic and organic constituents.
\end{abstract}


The user of the enclosed data base should be familiar with Microsoft Access and structured query language (SQL). This data base is structured in a relational data base data model with tables containing data in columns that fit into predefined categories. The data base structure is designed to support the ground-water-flow and solute-transport modeling of natural attenuation processes at Canal Creek. After meeting with the project staff, a set of basic criteria for inclusion in the data base was outlined. These were used as a starting point for the initial data base design. After further discussions, a final revised set of criteria was established. This set was then translated into an appropriate field and file structure for the data base.

A full view of all the tables and fields in the data base and the overall structure of the data base is shown in an Adobe Acrobat PDF file named ERDiagram.pdf included on this CD-ROM. This graphical representation of the data-base relationships is provided as an aid to understanding the structure of the data base. The diagram is comprised of three basic elements: entity types, attributes, and relationships. An entity is an object that stores data and is represented by rectangles on the diagram. The data base stores information about sampling locations, samples collected for analyses, results of analyses performed on each sample, and information about the various types of sampling locations. The entity information is called an attribute and is represented by ovals on the diagram. Each entity type in the data base has the same set of attributes with different attribute values. All tables are related to one another through defined relationships using the primary keys shown in diamonds on the diagram.

Naming conventions are used for tables and fields. Names consist of whole words or phrases that describe the data contained in each table. All tables have a prefix of either 
"tbl" for basic data tables or "lut” for lookup tables, which are used to classify or quantify information in a data table. For example, "tblSample" is a table that contains basic data on samples, such as collection date and time, sample matrix, and sample location. The table "lutSampleType" is a lookup table that defines the type of sample that was collected, such as a replicate or duplicate sample.

Every table in the data base has a field or a combination of fields that uniquely identifies each record in the table. This unique identifier is called the primary key and is labeled (PK) in the data dictionary. Primary keys have an "_id" suffix. For example, the location_id field in the location table is the primary key for that table; no two records in the location table have the same value in the location_id field. This provides a method to identify one particular record in the table. When a field in one table matches the primary key of another table, this is referred to as a foreign key (FK). Foreign keys are labeled (FK) in the data dictionary. For example, the location_id field in the sample table is a foreign key in that table. The location_id field links the location table and the sample table.

Each row in a data table contains unique data for the categories defined by the columns. For example, the location table describes sampling locations with columns for latitude, longitude, elevation and so forth. The sample table describes the samples that were collected with columns for data such as sample date, sample method, sample matrix, and location. By linking the sample and location tables, the user can view data on both the sample and the location where the sample was collected.

A Data Dictionary is enclosed on this CD-ROM in an MS Word document named Data Dictionary. Instructions on how to read the data dictionary listings are provided with 
it. The data dictionary provides information on each table in the data base, including the table name, the number of fields and records, and the date and time the table was last updated. The tables are described in terms of the fields they contain, including field name, a brief description of the information in the field, and the type and size of the field. 


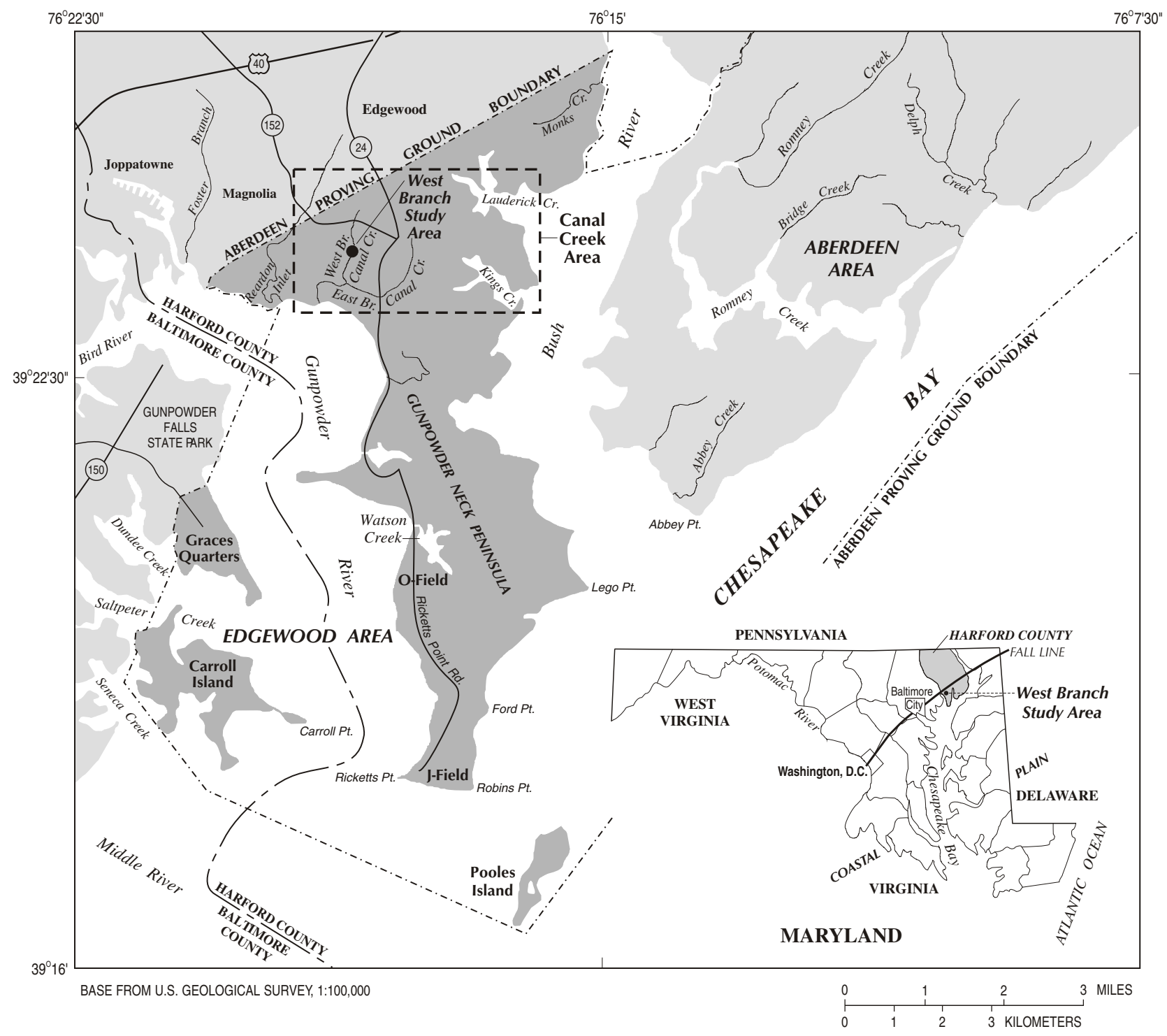

Figure 1. Location of Canal Creek area and West Branch study area, Aberdeen Proving Ground, Maryland (modified from Lorah and others, 1997, p. 5). 


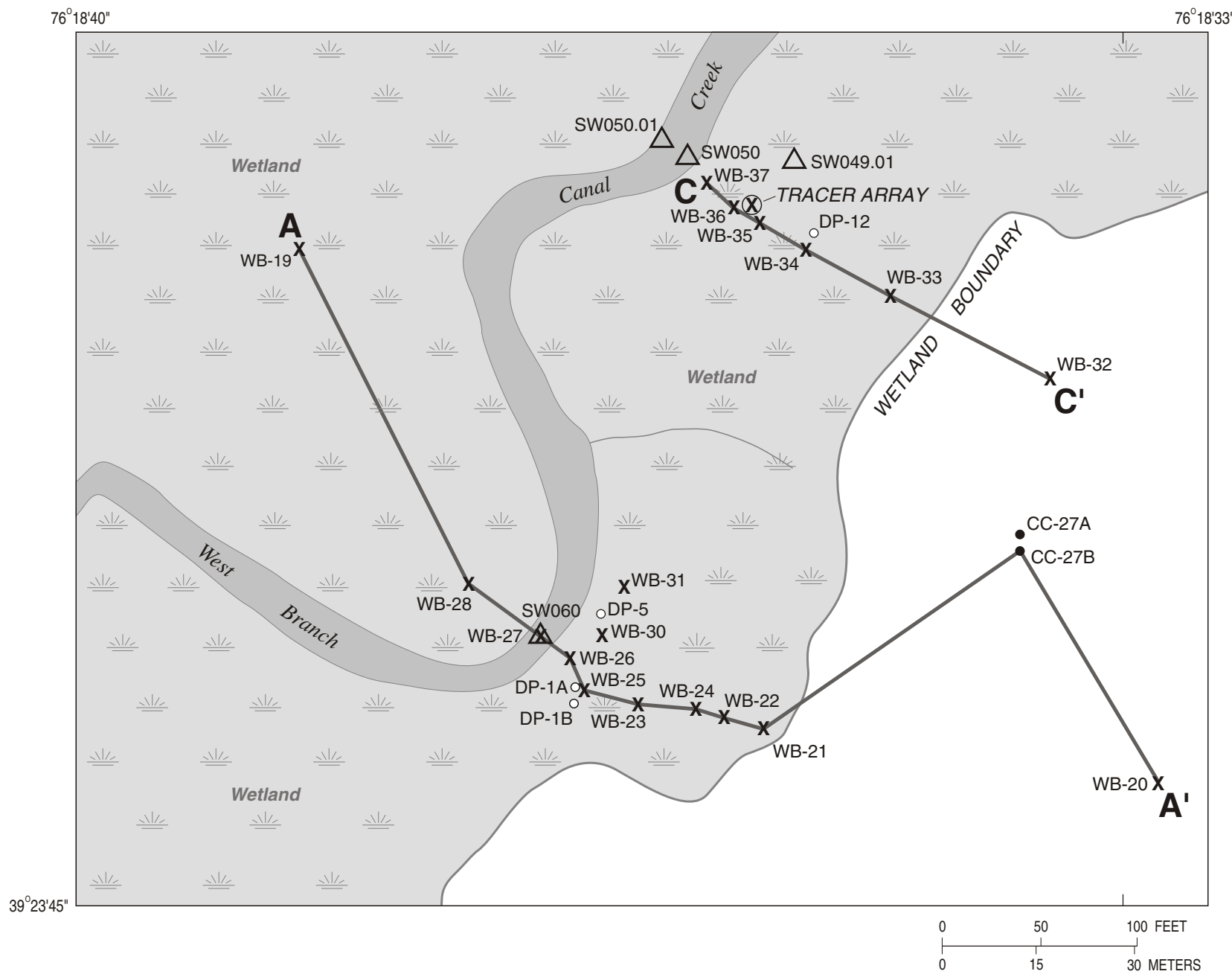

EXPLANATION

- $\quad$ 4" WELL FROM PREVIOUS STUDY

- 2" PIEZOMETER SITE

A-A' LINE OF SECTION
X $\quad 0.75$-INCH PIEZOMETER SITE

$\otimes$ TRACER ARRAY

SW060 $\triangle$ SURFACE-WATER SITE AND IDENTIFICATION NUMBER

$\begin{array}{cl}\text { CC-27A } & \\ \text { DP-12 } & \text { WELL OR PIEZOMETER } \\ \text { WB-20 } & \text { SITE NUMBER }\end{array}$

Figure 2. Locations of sampling sites and transects $A-A^{\prime}$ and $C-C^{\prime}$ in the wetland study area along West Branch Canal Creek, Aberdeen Proving Ground, Maryland (modified from Lorah and Clark, 1996, p. 106). 
Entity Relationship Diagram of the Digital Water-Quality Data Base for West Branch Canal Creek Area Aberdeen Proving Ground, Maryland

Version 1.1, October 25, 2000

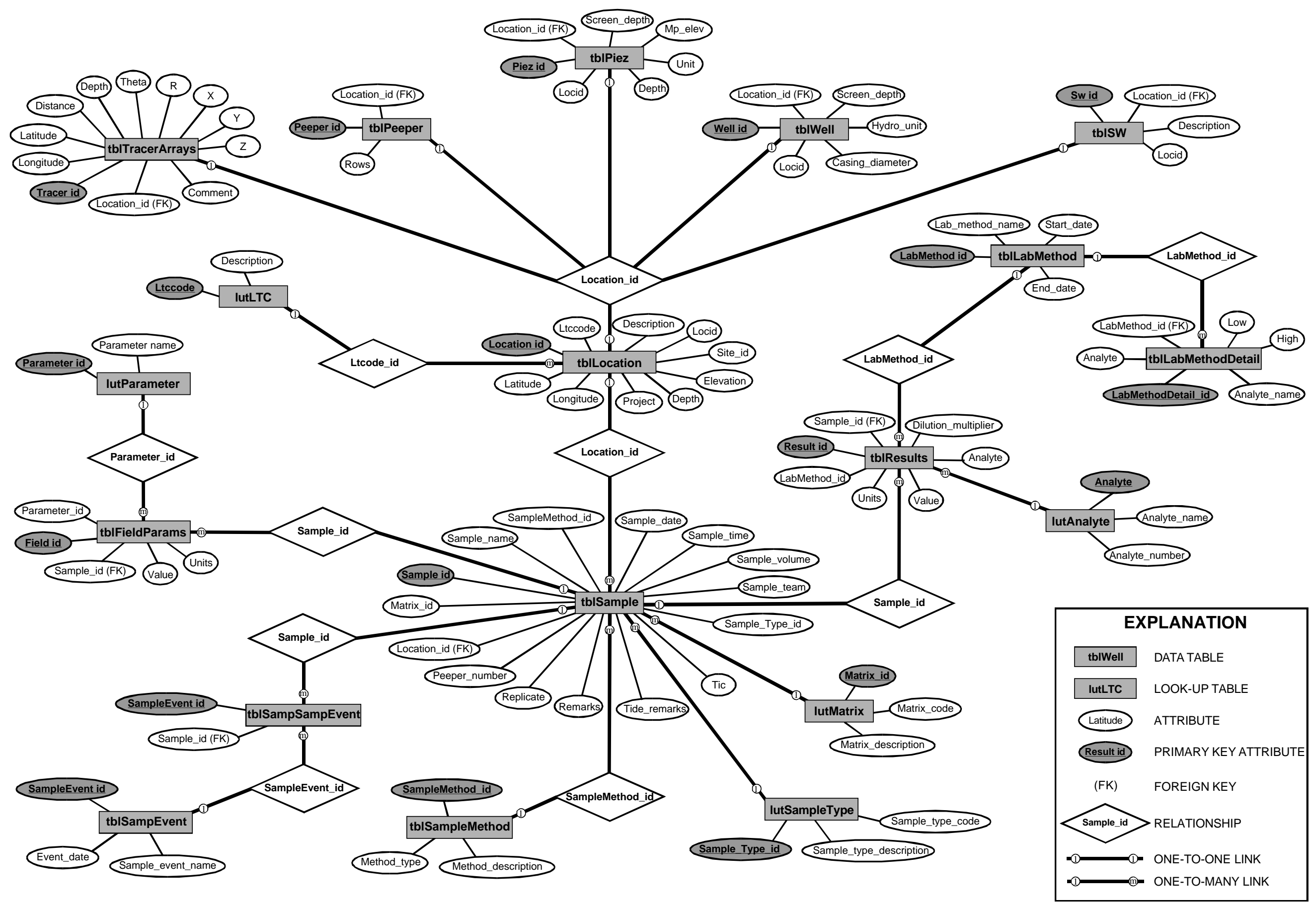




\title{
U.S. GEOLOGICAL SURVEY
}

\author{
Digital Water-Quality Data Base for the West Branch Canal Creek \\ Area, Aberdeen Proving Ground, Maryland \\ Open File Report OFR 01-63
}

[This is the \DISCLAIM.TXT file]

\section{DISCLAIMER}

This Compact Disc (CD-ROM) publication was prepared by the United States Geological Survey (USGS), an agency of the United States Government. Neither the United States Government nor any agency thereof nor any of their employees makes any warranty, expressed or implied, or assumes any legal liability or responsibility for the accuracy, completeness, or usefulness of any information, apparatus, product, or process disclosed in this report or represents that its use would not infringe privately owned rights. Reference therein to any specific commercial product, process, or service by trade name, trademark, manufacturer, or otherwise does not constitute or imply its endorsement, recommendation, or favoring by the United States Government or any agency thereof. Any views and opinions of authors expressed herein do not necessarily state or reflect those of the United States Government or any agency thereof.

The information contained on this CD-ROM has been approved for release by the Director of the USGS and has previously been published in a series of water-data reports. Although the data have been subjected to rigorous review and are substantially complete and accurate, the USGS reserves the right to revise the data pursuant to further analysis and review.

Although all data and software published on this CD-ROM have been used by the U.S. Geological Survey, no warranty, expressed or implied, is made by the U.S. Geological Survey as to the accuracy of the data and related materials and (or) the functioning of the software. The act of distribution shall not constitute any such warranty, and no responsibility is assumed by the U.S. Geological Survey in the use of these data, software, or related materials. 